The foregoing points are tempered by the observation that the obtained differences appeared in the first block of trials. These differences in performance then proceded from different levels on the first block across the ensuing trial blocks with little evidence of any divergence. It could be assumed that the intensity factor produced an interaction effect during this first block of trials. However, it was not possible to determine whether or not this was the case because of the low performance obtained. It is clear that this question merits further investigation.

In conclusion, the procedure of Grice et al (1966) may offer a viable approach to investigate the effects of stimulus variables on animal learning when control of background stimulation appears warranted.

\section{REFERENCES}

Champion, R. A. Stimulus-intensity effects in response evocation. Psychological Review, 1962, 69, 428-449.

Champion, R. A. Reduced stimulus intensity as a CS in GSR conditioning. Journal of Experimental Psychology, 1967, 73, 631-632.

Grice, G. R., \& Hunter, J. J. Stimulus intensity effects depend upon the type of experimental design. Psychological Review, $1964,71,247-256$.

Grice, G. R., Masters, L., \& Kohfeld, D. L. Classical conditioning without discrimination training: A test of the generalization theory of CS intensity effects. Journal of Experimental Psychology, 1966, 72, 510-513.

Hull, C. L. Stimulus intensity dynamism (V) and stimulus generalization. Psychological Review, 1949, 56, 67-76.

Kimble, G. A. Hilgard and Marquis' Conditioning and learning. New York: Appleton-Century-Crofts, 1961.

Kish, G. B. Avoidance learning to the onset and cessation of conditioned stimulus energy. Journal of Experimental Psychology, 1955, 50, 31-38.

Logan, F. A. A note on stimulus intensity dynamism (V). Psychological Review, 1954, 61, 77-80.

Logan, F. A., \& Wagner, A. R. Direction of change in CS in eyelid conditioning. Journal of Experimental Psychology, $1962,64,325-326$.

Perkins, C. C., Jr. The relation between conditioned stimulus intensity and response strength. Journal of Experimental intensity and response strength.

Schwartz, M. Conditioned-stimulus variables in avoidance learning. Journal of Experimental Psychology, 1958, 55, 347-351.

(Received for publication April 25, 1973.)

\title{
Social attraction among and between albino and hooded rats*
}

\author{
BIBB LATANÉ, JOHN EDWARDS $\dagger$, \\ CLAUDE STEELE $\dagger \dagger$, and DAVID WALTON $\dagger+\dagger$ \\ Ohio State University, Columbus. Ohio 43210
}

Cross- or within-strain pairs of albino and hooded rats were allowed to affiliate freely in an open field. All rats, whether male or female, albino or hooded, were highly gregarious, and this gregariousness increased over days. Although hooded rats showed more defecation and immobility than did albinos, there were no differences in overall social attraction, and rats in cross-strain pairs did not differ from rats in same-strain pairs. The results suggest that emotionality does not necessarily lead to affiliation in rats and that sociability does not depend on similarity of such static stimulus characteristics as fur color.

Male albino rats are very much attracted to other male albino rats. When tested in same-sex pairs in an open field, they stay much closer to each other than would be expected by chance (Latané, 1969) and often spend upwards of $50 \%$ of their time in direct physical contact. The attraction exhibited by male albino rats increases over days of testing, probably because competing exploratory and fear responses drop out as the field becomes familiar (Eckman, Meltzer, \& Latané, 1969; Latané \& Walton, 1972). These results are well established for male albino rats; it is unknown whether they also hold for females or for other rat strains.

Male albino rats appear to reduce fear for each other. They defecate less when tested in pairs than when tested alone and show less immobility or freezing (Latané, 1969; Latané \& Glass, 1968; Latané, Joy, Meltzer, Lubell, \& Cappell, 1972; Latané, Poor, \& Sloan, 1971; Latané \& Werner, 1971). This opens up the possibility

*This research was partially supported by NSF Grants GS 1239 and GS 2292. Request reprints from Bibb Latané, 404-C West 17th Ave., Columbus, Ohio 43210.

+ Now at Loyola University, Chicago, Ill. 60626.

+ Now at University of Utah, Salt Lake City, Utah 84112.

$++N$ ow at Marshall University, Huntington, w. Va. 27501. that fear reduction is a motivation for social approach in rats. If so, then it might be expected that rats differing in fearfulness should also differ in gregariousness. Hooded rats typically show greater signs of emotionality than do albino rats (Wilcock \& Broadhurst, 1967); it is unknown whether they also show greater sociability.

Male albino rats are much more attracted to other male albino rats than they are to a variety of nonsocial objects, whether moving or still (Latané \& Glass, 1968), familiar or unfamiliar (Latané, Poor, \& Sloan, 1971), warm or cold, or previously associated with positive reinforcement or not (Latane \& Werner, 1971). These results suggest that the movement of another rat, its responsiveness, or the opportunity to interact with it may be important determinants of social attraction. It would be interesting to see whether albino rats are also attracted to rats of another strain or whether there is any intrinsic preference for a member of one's own strain, independent from its responsiveness or the opportunity for interaction.

The present experiment attempts to: (1) Test the generality of social attraction and the days effect by examining them with two different strains of rats and both sexes; (2) provide a new test of a possible fear-affiliation relationship by testing social attraction in two rat strains known to differ in fearfulness; and (3) see whether there is any sign of social discrimination or own-strain preference in rats by testing both same-strain and cross-strain pairings.

\section{METHOD \\ Design}

Sixteen same-sex pairs of rats were tested each day for 10 days in each of the three experimental conditions. Rat pairs consisted of either two albino rats, two hooded rats, or one albino and one hooded rat. Each rat was tested with the same partner throughout. Within each condition, half the pairs consisted of male rats and half of female rats. 


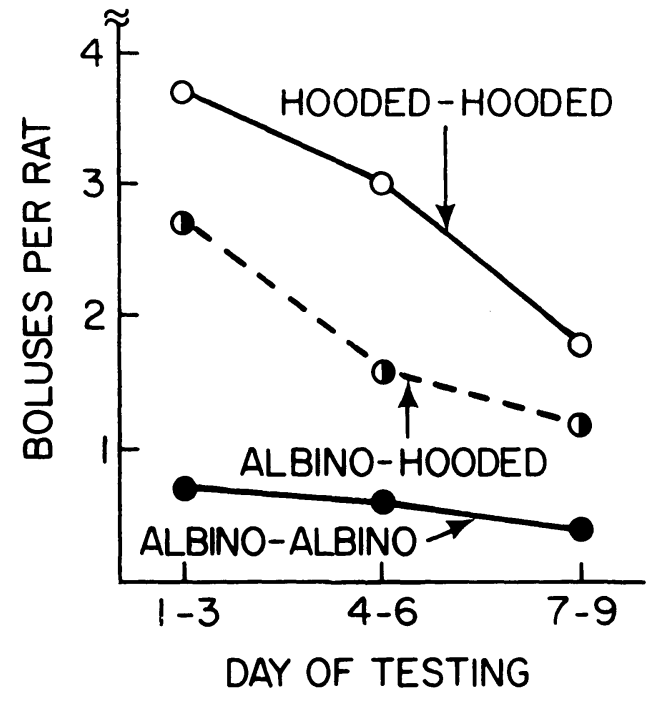

Fig. 1. Mean number of boluses per rat as a function of strain, pairing, and day of testing.

\section{Subjects and Apparatus}

Experimentally naive Sprague-Dawley albino rats from commercial suppliers (48) and hooded Long-Evans rats bred from the Ohio State colony (48) were housed for 17 days before testing in single cages on an ab lib food and water regime. Animals were approximately 70 days old at the start of testing.

Rats were observed in pairs in circular open fields, $4 \mathrm{ft}$ in diam and painted flat white (Latané, 1969). The floor was marked into 49 numbered sections by a series of concentric circles and radii. A shaded $40-\mathrm{W}$ light bulb hung $2 \mathrm{ft}$ above the center of the field.

\section{Procedure}

Each rat pair was allowed to move about the open field freely for $5 \mathrm{~min}$ a day for 9 consecutive days. Os recorded the amount of time rats spent in direct physical contact (excluding tail-to-tail contact), number of fecal boluses, and the locations of each animal at 10 -sec intervals. The average distance between rats was calculated from these locations.

\section{RESULTS \\ Defecation}

Hooded rats, which have a reputation for emotionality, defecated substantially more than did albinos $(2.8$ vs $0.6, \mathrm{p}<.001){ }^{1}$ However, defecation in mixed pairs was intermediate between the same-strain pairs, and did not differ significantly from the average of the same-strain pairs (Fig. 1).

Defecation declined monotonically over days from a mean of 2.4 boluses on Day 1 to less than 1 on the last day of testing $(p<.001)$. The effect of sex was not significant.

\section{Immobility}

Another manifestation of fear in rats is freezing, i.e., staying in the same location while crouching, grooming, or swaying slightly. An immobility index was derived from the location data by counting the number of consecutive observation intervals during which a rat remained in the same numbered area.

Hooded rats were more immobile than albinos, remaining in the same location on $19 \%$ of the 10 -sec observation periods as compared to $8 \%(\mathrm{p}<.001)$. Mixed-strain pairs, however, did not differ significantly from same-strain pairs.

Males were more immobile than females (17\% vs $9 \%$, $\mathrm{p}<.001)$. The effect of days was not significant.

\section{Time in Contact}

Pairs of albino rats spent somewhat more time in contact than did hooded pairs $(p<.08)$. Cross-strain pairs, however, did not differ from the average of the same-strain pairs, suggesting that rats do not discriminate in social attraction against rats of different strains (Fig. 2).

Mean time in contact increased monotonically from $33 \%$ on Day 1 to over $50 \%$ on the last day of testing $(p<.001$.). The main effect of sex was not significant, nor were any interactions.

\section{Distance}

Although albino pairs spent more time in contact than hooded pairs, they showed higher average distances between them $(p<.05)$. This suggests that the typical pattern of interactions for the two species may be somewhat different. However, as with time in contact, average distance for animals in mixed pairs did not differ from the average of the same-strain pairings, indicating that rats find a member of a strain different from their own no less and no more attractive than a member of their own strain.

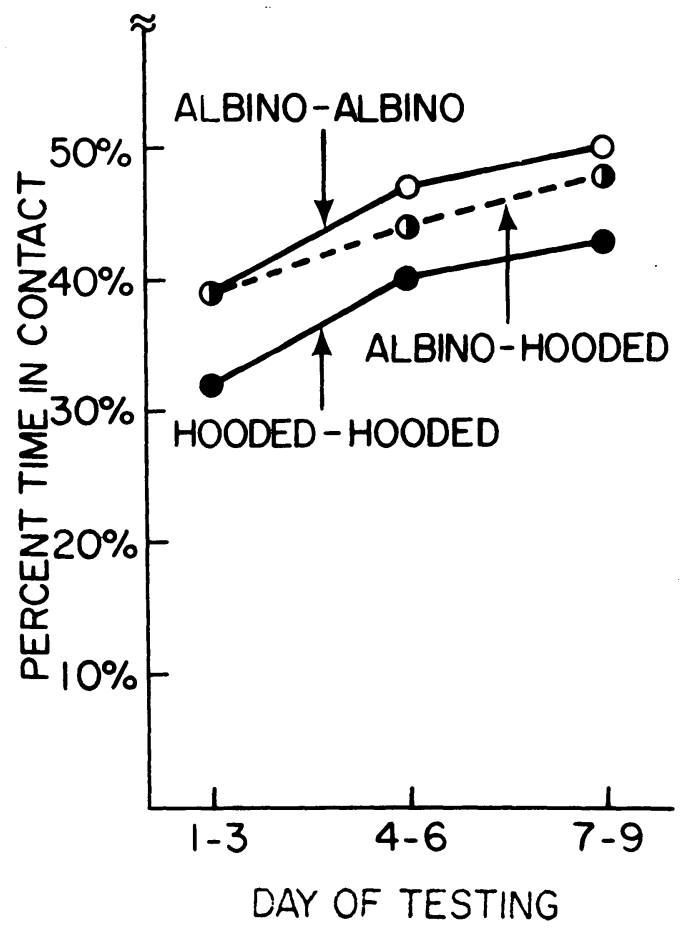

Fig. 2. Percent time in contact as a function of strain, pairing, and day of testing. 
There were no differences due to sex, but a substantial (36\%) drop in average distance over days $(\mathrm{p}<.001)$.

\section{Intercorrelations}

The gregariousness measures, distance and contact, were highly and negatively correlated (Table 1). Defecation and immobility showed a very slight (but significant) positive correlation. Correlations between gregariousness and measures of fear were inconsistent.

These data as well as several other measures were also factor analyzed using a varimax rotation. The two main factors together accounted for $70 \%$ of the variance. Contact and distance loaded highest on Factor 1, which could be called "gregariousness." Factor 2 might be termed "emotionality" or "inactivity." Defecation loaded fairly strongly on both factors.

\section{DISCUSSION}

Almost all the previous research in this series has been done with male albino rats as Ss. In the present study, hooded males and females of both strains were also tested. Although there were differences in emotionality indices between the sexes and strains, all rats showed a substantial degree of social attraction, and, for all rats, attraction increased over days. These findings replicate previous results and suggest that they are not limited either to albinos or to males.

Albino and hooded pairs showed significant or near-significant differences on each gregariousness measure. However, these differences were in opposite directions, with hooded rats staying closer together $(p<.05)$ but spending somewhat less time in actual physical contact $(\mathrm{p}<.08)$ than albino pairs. This difference in pattern of interaction may result from the greater visual acuity reported for hooded rats (Hermann, 1968); albino rats typically seem to show little interest in each other unless they are in direct physical contact.

In a classic series of studies, Schachter (1959) demonstrated that fear leads to affiliation in humans. A number of studies with rats have shown that rats are less fearful when in social contact than when alone (Davitz \& Mason, 1955; Latané, 1969; Latané \& Glass, 1968; Morrison \& Hill, 1967). In light of these findings, Latané (1969) suggested that one reason rats may affiliate is to reduce fear. If this were so, one might expect that fearful rats would be more affiliative than nonfearful rats, since they would have more to gan from affiliation.

This expectation has received little support. Rats are less, not more, affiliative in unfamiliar, fear-inducing environments than in environments with which they have become familiar (Eckman, Meltzer, \& Latané, 1969; Latané \& Walton, 1972). Rats are less, not more, affiliative when exposed to fear-inducing electric shocks (Latané, Friedman, \& Thomas, 1972). These findings are somewhat equivocal, however, since it is possible that fear was manipulated so strongly as to inhibit directly the motor activities needed to produce social contact.

The present experiment provides a different kind of evidence relevant to this issue. As in previous studies (e.g., Wilcock \& Broadhurst, 1967), hooded rats showed a substantially higher degree of emotionality than did albinos. Yet, overall, they were no more affiliative. Correlational analyses also showed that two measures of emotionality, defecation and immobility, had opposite relationships with gregariousness. Again, it appears that fear does not necessarily lead to affiliation in rats. Lindzey, Winston, \& Roberts (1965) found a similar lack of correlation between emotionality and sociability across five inbred strains of mice.

Albino and hooded rats were as attracted to each other as
Table 1

Intercorrelations Among the Variables and Factor Loadings (Based on 420 Observations)

\begin{tabular}{|c|c|c|c|c|c|}
\hline & \multirow[b]{2}{*}{ Contact } & \multirow[b]{2}{*}{ Distance } & \multirow[b]{2}{*}{ Boluses } & \multicolumn{2}{|c|}{ Factor 1 Factor 2} \\
\hline & & & & $\begin{array}{l}\text { Gregari- } \\
\text { ousness }\end{array}$ & $\begin{array}{l}\text { Emotion- } \\
\text { ality }\end{array}$ \\
\hline Contact & - & & & +.85 & +.01 \\
\hline Distance & -.69 & -- & & -.87 & -.34 \\
\hline Boluses & -.40 & .24 & -- & -.59 & +.55 \\
\hline Immobility & .17 & -.26 & .10 & +.11 & +.76 \\
\hline
\end{tabular}

were same-strain pairs. It is apparent that the obvious difference in fur color between hooded and albino rats and possible differences in smell, etc., do not make much difference to the rats themselves. This result is consistent with findings by Latané, Joy, Meltzer, Lubell, \& Cappell (1972), that albino rats seem to be at least as much attracted to other rats who are dyed a different color, shaved, or perfumed as they are to normal rats, and are as attracted when their sight or smelling ability is impaired as when they are normal.

Unpublished evidence from our laboratory, however, shows a strong decline in attraction when rodents are tested in cross-species pairs (i.e., rats with gerbils, gerbils with hamsters, etc.) as compared to within-species pairs. This, of course, contrasts with the present results, which show no difference between cross- and same-strain pairings, suggesting that somewhere between the level of the strain and the species there is a sort of boundary. Discovering the nature of this boundary will be an important contribution, especially as is does not seem to depend on static stimulus qualities such as appearance, smell, etc.

\section{REFERENCES}

Davitz, J. R., \& Mason, D. J. Socially facilitated reduction of a fear response in rats. Journal of Comparative \& Physiological Psychology, 1955, 48, 149-151.

Eckman, J., Meltzer, J., \& Latané, B. Gregariousness in rats as a function of familiarity of environment. Journal of Personality \& Social Psychology, 1969, 11, 107-114.

Hermann, G. Beiträge zur Physiologie des Rattenauges. Zeitschr̀ift für Tierpsychologie, 1958, 15, 462-518.

Latané, B. Gregariousness and fear in laboratory rats. Journal of Experimental Social Psychology, 1969, 5, 61-69.

Latané, B., Friedman, L., \& Thomas, J. A ffiliation in rats under stress. Psychonomic Science, 1972, 27, 39-40.

Latané, B., \& Glass, D. C. Social and nonsocial attraction in rats. Journal of Personality \& Social Psychology, 1968, 9, 142-146. Latané, B., Joy, V., Meltzer, J., Lubell, B., \& Cappell, H. Stimulus determinants of social attraction in rats. Journal of Comparative \& Physiological Psychology, 1972, 79, 13-21.

Latané, B., Poor, D., \& Sloan, L. Familiarity and attraction to social and nonsocial objects by rats. Psychonomic Science, $1972,26,171-172$.

Latané, B., \& Walton, D. Effects of social deprivation and familiarity with the environment on social attraction in rats. Psychonomic Science, 1972, 27, 9-11.

Latané, B., \& Werner, C. Social and nonsocial sources of attraction in rats. Psychonomic Science, 1971, 24, 147-148. Lindzey, G., Winston, H. D., \& Roberts, L. E. Sociability, fearfulness, and genetic variation in the mouse. Journal of Personality \& Social Psychology, 1965, 1, 642-645.

Morrison, B. J., \& Hill, W. F. Socially facilitated reduction of the fear response in rats raised in groups or in isolation. Journal of Comparative \& Physiological Psychology, 1967, 63, 71-76. Schachter, S. The psychology of affiliation. Stanford: Stanford University Press, 1959

Wilcock, J., \& Broadhurst, P. L. Strain differences in emotionality: Open-field and conditioned avoidance behavior in the rat. Journal of Comparative \& Physiological Psychology, 1967,63, 335-338.

\section{NOTES}

1. All $p$ values are based on analyses of variance and represent two-tailed tests.

(Received for publication May 7, 1973.) 